\title{
Duality in Identifiable System Biology of DNA Injury and Contrasting DNA Repair
}

\author{
Lawrence M Agius* \\ Department of Pathology, University Of Malta Medical School, Malta Europe
}

Submission: November 01, 2018; Published: November 16, 2018

"Correspondence Address: Lawrence M Agius, Department of Pathology, Mater dei hospital, Tal-Qroqq, University of Malta Medical School, Malta, Europe

\section{Abstract}

Systems of participation are self-projected upstream pathways in the cooperative pathways of contrast dimension in the further realization of DNA injury on the one hand and of pathways of attempted DNA repair.The system biology of DNA repair incorporates both cell proliferation and anti-apoptosis as further conformational identity in the establishment of carcinogenesis. Profiles of identity of gene expression modules indicate the emergence of hyper-expression indices in the performance attributes for further transformation as well-documented in the establishment of tumorigenesis. Performance identity is a well-characterized influence in the gene expression modulation of DNA that is injured in terms of performance of the resultant attempts at DNA repair.

\section{Introduction}

Although great progress has been achieved regarding the genetic basis of colorectal cancer, the complex role of cell-cell communication and cytokine-induced signaling during pathogenesis remains poorly understood [1]. STAT3 is conceptually an ideal target in terms of the intra-cytoplasmic mode of targeting of transcription activities of various multiple genes within the all-dominating roles for functional equivalents of physiologic mechanistic and molecular dynamics for further stimulation of protein kinases.Inositol-requiring enzyme 1alpha-X-box-binding protein singling promotes carcinogenesis of hepatocellular carcinoma by regulating activation of the IL6-STAT3 signaling pathway [2]. It is within such milieu that the dynamic equilibrating dimensions of onset and progression of gene transcription accounts for the over-stimulatory pathways leading to oncogenesis.

\section{Mechanistic Projections}

It is further to such considerations that the significant degree of stimulation of injury-induced reparative processes both induce and further propagate the development also of stromal participation in oncogenesis.In such terms, the degree of participation of NF-kappaB and of Interleukin-6 allows for the inhibition of apoptosis and the onset suppression dimensions of immune suppression. The metastatic potential of malignanttumors is participant mechanistic pathway modulation in the realization of the ongoing positive feedback pathways leading inherently to malignant transformation. c-Jun and STAT3 are critical regulators of liver carcinogenesis and progression [3]. Evidence supports a critical role for Apurinic/apyrimidinic endonuclease 1 in inducing activation of the EGFR-STAT3 signaling axis in response to acidic bile salts, a main risk factor for Barrett's carcinogenesis [4].

The conceptually dramatic and inducing dynamics of onset of malignant change is further confirmatory index for a nonphysiologic modulation of a series of pathway inducers in involve further dimension for establishment of tumor angiogenesis which is inherently centered in the tumor micro-environment. Signal transducers and activators of transcription especially STAT3, becomes persistently activated in a majority of solid and hematopoietic malignancies as in melanoma, multiple myeloma, breast, prostate, ovarian and colon cancer, thus contributing to malignant transformation and progression[5]. In such cases the incremental over-stimulation of chronic inflammation allows a permissive re-appraisal influence in gene transcription that results from the growth-factor and cytokine modulatory roles in a inducing environment.

\section{Participation}

The theorem of participation is strict cooperative dysfunctionality of the over-stimulatory but also highly selective indices for overt increase in gene expression profile activity. Colorectal cancer is causally linked to DNA repair defects and inflammatory bowel disease; the DNA repair protein poly(ADPribose) polymerase- 1 is over expressed in colorectal cancer and this suppresses tumor initiation following DNA alkylation 
in a MGMT-dependent manner but promotes inflammationdriven tumor progression [6]. In terms that are induced agency developments in corresponding milieu, it is the inflammatory and immune-evasive mechanisms that establish realization of dysfunctional cell hyper-proliferation and invasion of tissues and micro-environment.STAT3 activation by E6 is essential for the differentiation-dependent Human papillomavirus18 life cycle [7]. The dynamics of the molecular signatures responsible for hepatocellular carcinogenesis are not fully understood but involve induced chronic liver cell injury by HBsAg-specific CD8+ $\mathrm{T}$ lymphocytes [8]. It is further to such considerations that the inhibition of STATs, in particular STAT3, that is paramount index pathway series in the prolongation of cell survival and the establishment of anti-apoptosis of transforming cells.

The dual participation of both genetic and epigenetic influences involves the prolongation of cell survival not only in terms of anti-apoptosis but also the implied duality of the cell proliferation within contextual establishment of angiogenesis in the micro-environment.miR-148a is an indirect tumor suppressor that modulates colitis and colitis-associated tumorigenesis by suppressing the expression signaling by NF-kappaB and STAT3 and their pro-inflammatory consequences [9]. The distributional significance of the evolving micro-environment re-modeling is system biology of the migrating endothelial cells from bone marrow precursors.It is within the inherently biologic attribute functionality of such endothelial cells that the whole gamut dimensionality of oncogenesis both assumes and further propagates the biologic establishment of anti-apoptosis.

\section{Performance}

The performance attributes are well-recognized dimensions that cooperate as system over-expression of several genes with the additional contextual performance of indices of strictly non-receptor tyrosine kinases that enhance intra-cytoplasmic trafficking and subsequent translocation into the nuclear micro-environment. Human hepatitis B virus activates STAT3 signaling in hepatocytes to foster its own replication and also to prevent apoptosis of infected cells, thus promoting HBVrelated carcinogenesis [10].The distributional hierarchy of the predominant intra-cytoplasmic dynamics of STAT3 allows for an over-expression of specific genes that earmark the malignant transformation phases in evolving carcinogenesis. Suppression of cytokine signaling 3 is an important negative regulator of IL6/JAK/STAT3 signaling pathway appears to be early critical determinant of carcinogenesis [11].

\section{Physiologic Dysfunctionality}

The concept of physiologic dysfunctionality is a selfcontrasting dimension centered, in most instances, on established distributional dynamics of transcription factors such as STAT3. Histone deacetylases are important enzymes affecting epigenetic relation and play a crucial role in human carcinogenesis; B1, a novel HDAC inhibitor, induces apoptosis through the regulation of STAT3 and NF-kappaB [12]. It is further to be realized the dimensions of such abnormal distributional patterns that gene transcription can be re-defined as mal-distribution of systems of gene suppression or as gene-over-expression pathways.

Relocation dynamics allow permissive induction of microenvironmental modulation as a strictly serial phenomenon in terms inherent to the development and further participation in oncogenic pathways of conclusive involvement of dual systems in evolutionary terms.Inflammation appears to have a paramount role in glioma genesis, malignant progression and tutor aggressiveness in the central nervous system micro-environment [13]. The reappraisal phenomenon of gene repair and particularly of epigenetic events is key dimension in the inclusion of stem cell biology and of such elements as migratory endothelial cells that multiply and further augment systems of participation in oncogenesis.

\section{Epigenesis}

Promotional events in epigenesis incur the cytokine systems biology as further projected by the emergence of gene expression modulation.The central and upstream pathways to STAT3 dysfunctionality allow for the cooperative enhancement of redistributed transcription factors as borne out by the mechanistic progression of intermediate modulators in oncogenesis. The tumor suppressor functions of the breast cancer susceptibility gene 1 (BRCA1) extend beyond DNA repair to include metabolic endpoints such as glycolysis and offers a window of opportunity for ovarian cancer chemoprevention [14].

The significance of re-distribution is itself centered on the progressive enhancement of further self-conformation of molecular species as strictly dictated by gene over-stimulation of especially STAT3. C-terminal truncated hepatitis B virus X protein regulates tumorigenicity, self-renewal and drug resistance via STAT3/Nanog signaling pathway [15].

Confirmatory and progressive protein sequence evolution allow for significant performance re-establishment as significant identifying features as index projections in gene expression. Cytolethal distending toxin promotes carcinogenesis induced by wild-type Helicobacter hepaticus by enhancing double strand breaks and activation of the Tumor necrosis factor alpha/IL6-Stat3 signaling pathway [16].Mirror-image dimensions are required and enhancing systems of duality that incorporate the further conformational identities of idealized protein-protein interactivity.

\section{Concluding Remarks}

Promotional self-realization is a conceptual framework within the system profile of cancer biology as attested by the overall aggressiveness of tumors of influence as well identifiable within thefurthermilieu of carcinogenic inception and progression.It is significant to view the distinctive characterization of cell and nuclear injury in terms of a DNA that is overall outline dynamics of intra-cytoplasmic events as induced by STAT3. 
The cooperative dimensions of transforming growth factor Beta and the participation of Nuclear-Factor kappaB and Hypoxiainducible factor that the performance injury in carcinogenesis both conforms to the dimensions of over-stimulation of gene expression and also identifies such over-expression of genes in terms of origin from DNA repair attempts at re-constitution of the DNA molecular structure and function.Determination of tumor induction is itself a comprehensive dimension of gene targeting as indeed proposed by systems of upstream pathway progression and also especially of interactivity within contextual reconstruction of integral pathway identity and performance.It is within the established profiles for DNA injury that the repair mechanisms of DNA are self-projected performance indices of the resultant progressive carcinogenesis as indeed professed by the performance attributes for further progression of cell hyperproliferation and spread.

\section{References}

1. De Oliveira T, Ramakrishnan M, Diamenti MA, Ziegler PK, Brombacher $\mathrm{R}$, et al. (2018) Loss of Stat6 affects chromatin condensation in intestinal epithelial cells causing diverse outcome in murine models of inflammation-associated and sporadic colon carcinogenesis. Oncogene.

2. Fang P, Xiang L, Huang S, Jin L, Zhou G, Zhuge L, et al. (2018) IRE1apha_ XBP1 singling pathway regulates IL-6 expression and promotes progression of hepatocellular carcinoma. Oncol Lett 16(4): 4729-4736.

3. Roderfeld M, Padem S, Lichtenberger J, Quack T, Weiskirchen R, et al. (2018) Schistosoma mansoni egg secreted antigens activate HCCassociated transcription factors c-Jun and STAT3 in hamster and human hepatocytes. Hepatology.

4. Bhat AA, Lu H, Soutto M, Capobianco A, Rai P, et al. (2018) Exposure of Barrett's and oesophageal adenocarcinoma cells to bile acids activates EGFR-STAT3 signaling axis via induction of APE1. Oncogene.

5. Laudisi F, Cherubini F, Monteleone G, Stolfi C (2018) STAT3 interactions as potential therapeutic targets for cancer treatment. Int J Mol Sci 19(6).
6. Dorsam B, Seiwert N, Foersch S, Stroh S, Nagel G, et al. (2018) PARP1 protects against colorectal tutor induction, but promotes inflammation-driven colorectal tumor progression. Proc Natl Acad Sci USA 115(17) :E4061-E4070.

7. Morgan EL, Wasson CW, Hanson L, Kealy D, Pentland I, McGuire V et al. (2018) STAT3 activation by E6 is essential for the differentiationdependent HPV18 life cycle. PLoS Pathog 14(4).

8. Nosaka T, Naito T, Hiramatsu K, Ohtani M, Nemoto T, et al. (2017) Gene expression profiling of hepatocarcinogenesis in a mouse model of chronic hepatitis B. PLoS One 12(10).

9. Zhu Y, Gu L, Li Y, Lin X, Shen H, et al. (2017) miR-148 inhibits colitis and colitis-associated tumorigenesis in mice. Cell Death Differ 24(12): 2199-2209.

10. Hosel M, Quasdorff M, Ringelhan M, Kashkar H, Debey Pascher S, et al. (2017) Hepatitis B virus activates signal transducer nd activator of transcription 3 supporting hepatocyte survive and virus replication. Cell Mol Gastroenterol Hepatol 4(3): 339-363.

11. Wei L, Huang Y, Zhao R, Zhang J, Liu Q, et al. (2018) Detection of promoter methylation status of suppressor of cytokine signaling 3 (SOCS3) in tissue and plasma from Chinese patients with different hepatic diseases. Clin Exp Med 18(1): 79-87.

12. Cheng MH, Wong YH, Chang CM, Yang CC, et al. (2017) B1, a novel HDAC inhibitor, induces apoptosis through the regulation of STAT3 and NF-kappaB. Int J Mol Med 39(5): 1137-1148.

13. Mustafa AG, Punganuru SR, Madala HR, Al Obaide M, Srivenugopal KS (2017) The process and regulatory components of inflammation in brain oncogenesis. Biomolecules 7(2).

14. Chiyoda T, Hart PC, Eckert MA, McGregor SM, Lastra RR, et al. (2017) Loss of RBCA1 in the cells of origin of ovarian cancer induces glycolysis: a window of opportunity for ovarian cancer chemoprevention. Cancer Prev Res (Phila) 10(4): 255-266.

15. Ching RHH, Sze KMF, Lau EYT, Chiu YT, Lee JMF, et al. (2017) C-terminal truncated hepatitis B virus X protein regulates tumorigenicity, selfrenewal and drug resistance via STAT3/Nanog singling pathway. Oncotarget 8(14): 23507-23516.

16. Ge Z, Feng Y, Ge L, Parry N, Muthupalani S, et al. (2017) Helicobacter hepaticus cytolethal distending toxin promotes intestinal carcinogenesis in 129Rag2-deficient mice. Cell Microbiol 19(7).

\section{Your next submission with Juniper Publishers will reach you the below assets}

- Quality Editorial service

- Swift Peer Review

- Reprints availability

- E-prints Service

- Manuscript Podcast for convenient understanding

- Global attainment for your research

- Manuscript accessibility in different formats

( Pdf, E-pub, Full Text, Audio)

- Unceasing customer service

Track the below URL for one-step submission https://juniperpublishers.com/online-submission.php 